Check for updates

Cite this: Chem. Sci., 2019, 10, 2785

¿ All publication charges for this article have been paid for by the Royal Society of Chemistry

Received 31st October 2018 Accepted 3rd January 2019

DOI: $10.1039 / \mathrm{c} 8 \mathrm{sc} 04854 a$

rsc.li/chemical-science

\section{Activatable near-infrared emission-guided on- demand administration of photodynamic anticancer therapy with a theranostic nanoprobe $\uparrow$}

\author{
Rongchen Wang,,$^{\mathrm{a}}$ Kaikai Dong, $,^{\mathrm{b}} \mathrm{Ge} \mathrm{Xu},{ }^{a}$ Ben Shi, ${ }^{a}$ Tianli Zhu, ${ }^{\mathrm{a}}$ Ping Shi, (D) *b \\ Zhiqian Guo, (iD ${ }^{a}$ Wei-Hong Zhu (iD) a and Chunchang Zhao (iD) *a
}

\begin{abstract}
Development of theranostic probes that can be used to identify tumors and direct the on-demand drug administration to cancers is ongoing but remains challenging. Herein, we report a theranostic platform composed of a $\mathrm{H}_{2} \mathrm{~S}$-activated imaging probe and a light-sensitive drug. The designed probe affords advantages of $\mathrm{H}_{2} \mathrm{~S}$-activated NIR emission light-up and efficient ${ }^{1} \mathrm{O}_{2}$ generation, enabling the selective visualization of $\mathrm{H}_{2} \mathrm{~S}$-rich cancers and the subsequent imaging-directed on-demand light exposure to the detected cancers while leaving normal tissues untouched. Such controllable administration of photodynamic anticancer therapy maximizes the therapeutic efficiency and minimizes side effects. This work should facilitate significant advances toward precise diagnosis and treatment of cancer.
\end{abstract}

\section{Introduction}

Precise cancer treatment relies on maximizing the toxic effect of anticancer drugs to tumor sites while minimizing the side effects to normal regions. ${ }^{1}$ To date, theranostic prodrug systems with integrated diagnostic and therapeutic functions have been developed as promising tools in precision cancer medicine. ${ }^{2}$ These systems are particularly useful for cancer therapy, providing activated release of drugs and concomitant in situ drug tracking capability in response to endogenous stimuli (including $\mathrm{pH},{ }^{3}$ hypoxia, ${ }^{4}$ increased glutathione levels,${ }^{5}$ elevated oxidative stress, ${ }^{6}$ and specific enzyme overexpression ${ }^{7}$ ) and/or exogenous stimuli (including light ${ }^{8}$ and heat ${ }^{9}$ ). However, concurrent events including the diagnostic and therapeutic capabilities of the available theranostic prodrugs do not allow for diagnosis-directed on-demand therapy. Thus the search for image-guided prodrugs, in which the tumor can be diagnosed and the subsequent diagnosis controlled on-demand drug administration to the detected region could be realized, is ongoing but remains challenging.

Photodynamic therapy (PDT) is a potent noninvasive therapeutic modality for a variety of cancers. ${ }^{10}$ PDT treatment utilizes a photosensitizer that serves as a light-sensitive drug to

\footnotetext{
${ }^{a}$ Key Laboratory for Advanced Materials and Institute of Fine Chemicals, School of Chemistry and Molecular Engineering, East China University of Science \& Technology, Shanghai 200237, P. R. China. E-mail: zhaocchang@ecust.edu.cn

${ }^{b}$ State Key Laboratory of Bioreactor Engineering, East China University of Science and Technology, Shanghai 200237, P. R. China. E-mail: ship@ecust.edu.cn

$\dagger$ Electronic supplementary information (ESI) available: Procedures for synthesis, characterization data, and supplementary figures. See DOI: 10.1039/c8sc04854a

\$ These authors contributed equally to this work.
}

generate cytotoxic ROS upon light irradiation for disrupting cellular function and killing the cells in the exposed area. ${ }^{\mathbf{1 1}}$ As light can provide the advantages of a noninvasiveness mode and precise spatiotemporal controllability, light-sensitive photosensitizers will cause less treatment-related toxicity and fewer side effects on adjacent normal tissues when compared with conventional chemotherapeutic reagents. ${ }^{12}$ Thus, a theranostic prodrug that integrates a diagnostic probe and a light-sensitive drug would be rather attractive because the tumor can be monitored and then diagnosis can precisely guide the ondemand light exposure to the detected region while leaving normal tissues untouched. Notably, the precise spatial location of the PDT agent and the timing of implementation of the light illumination are critical to maximize the therapeutic effect.

Herein, in this work, we reported a theranostic prodrug for activatable near-infrared emission-guided on-demand administration of photodynamic anticancer therapy. Although the appealing strategy for developing activatable PDT agents has been demonstrated to be an efficient way to control PDT selectivity to cancer cells while leaving normal cells unharmed, the construction of such an activatable photosensitizer requires judicious molecular design and is nontrivial. ${ }^{13}$ The theranostic prodrug (TNP-SO) platform here was composed of a $\mathrm{H}_{2} \mathrm{~S}$-activated imaging probe, NIR-BSO and a light-sensitive drug, 3IBOD. The two units were linked by a short diethylene glycolamine spacer. Interestingly, NIR-BSO displayed $\mathrm{H}_{2} \mathrm{~S}$-dependent NIR emission light up, thus enabling the selective detection of $\mathrm{H}_{2} \mathrm{~S}$-rich cancer cells. More importantly, such cancer imaging precisely directed when and where to implement the light illumination of 3I-BOD to produce cytotoxic ROS for on-demand cancer therapy, thus maximizing the therapeutic efficiency and minimizing side effects. 


\section{Results and discussion}

The target compound TNP-SO was readily synthesized in a sequence of steps, as illustrated in Schemes 1 and S1. $\dagger$ The light-sensitive drug 3I-BOD was modified with compound 3 to afford 4 with the requisite cyanoacetamide function, which was incorporated into $p$-thiocresol substituted BODIPY via a Knoevenagel condensation reaction with aldehyde BODIPY $5,{ }^{\mathbf{1 4}}$ thus affording an intermediate 6 . Finally, conversion of a thioether unit with $m$-CPBA to a sulfoxide functional group produced the target theranostic prodrug TNP-SO in good yield. The identity and purity of all new compounds were verified by NMR and mass spectrometry.

It is known that elevated $\mathrm{H}_{2} \mathrm{~S}$ production is closely related to various cancers, such as ovarian, breast, and colorectal cancers. ${ }^{15}$ Accordingly, $\mathrm{H}_{2} \mathrm{~S}$-activated NIR emissions could provide a powerful tool for the accurate identification of these cancers. We first investigated the capability of TNP-SO as an activatable fluorescent probe toward $\mathrm{H}_{2} \mathrm{~S}$ under physiological conditions $\left(\mathrm{CH}_{3} \mathrm{CN} / \mathrm{PBS}\right.$, $1: 1, \mathrm{v} / \mathrm{v}, 20 \mathrm{mM}, \mathrm{pH} 7.4$, and room temperature). As shown in Fig. 1, TNP-SO showed a mild absorption and a strong absorption with maxima at 500 and $533 \mathrm{~nm}$, corresponding to NIR-BSO and 3I-BOD, respectively. Notably, the absorption of 3I-BOD partially obscures that of NIR-BSO owing to spectral overlap. Upon the treatment with $100 \mu \mathrm{M} \mathrm{H} \mathrm{H}_{2} \mathrm{~S}$, the absorption band at $500 \mathrm{~nm}$ decreased obviously accompanied by the emergence of a new absorption band around $655 \mathrm{~nm}$, affording a dramatic red-shift of $155 \mathrm{~nm}$. More importantly, this process activated a robust NIR fluorescence at $712 \mathrm{~nm}$ that produced about 137-fold enhancement upon excitation at $640 \mathrm{~nm}$. Such optical changes were ascribed to the conversion of TNP-SO into corresponding TNP-HS, proven by HRMS analysis (Fig. S1 $\dagger$ ). Collectively, TNP-SO exhibited $\mathrm{H}_{2} \mathrm{~S}$-triggered NIR emission light up, and thus preferable for $i n$ vivo visualization of $\mathrm{H}_{2} \mathrm{~S}$-rich cancers due to the deep penetration ability, minimal tissue absorption and low background autofluorescence in the NIR region. ${ }^{16}$
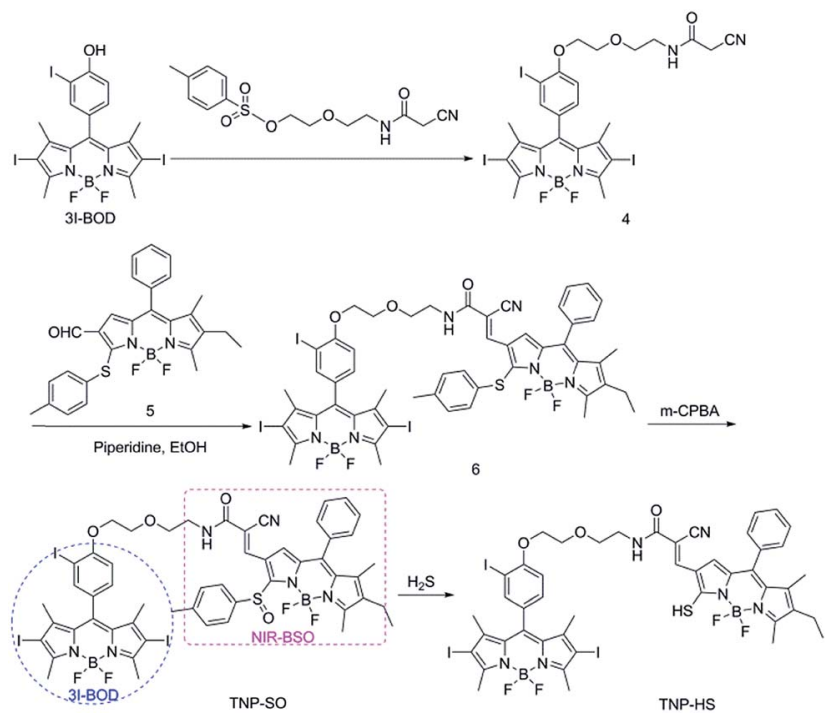

Scheme 1 Synthesis of the target compound TNP-SO.
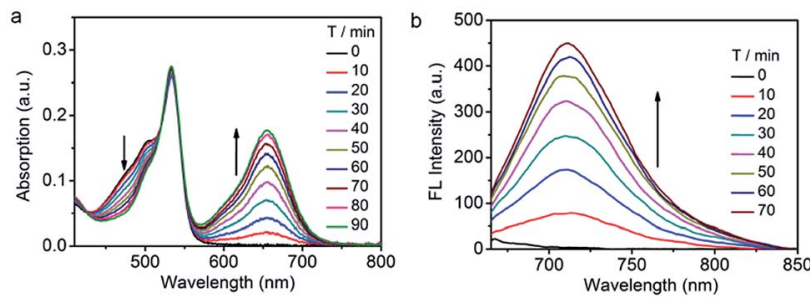

Fig. 1 Time-dependent (a) absorption and (b) emission spectral changes of TNP-SO $(5 \mu \mathrm{M})$ in the presence of $100 \mu \mathrm{M}$ NaHS under physiological conditions $\left(\mathrm{CH}_{3} \mathrm{CN} / \mathrm{PBS}, 1: 1, \mathrm{v} / \mathrm{v}, 20 \mathrm{mM}, \mathrm{pH} 7.4\right.$, and room temperature). $\lambda_{\mathrm{ex}}=640 \mathrm{~nm}$.

The photosensitizing generation of ${ }^{1} \mathrm{O}_{2}$ induced by the lightsensitive drug 3I-BOD in TNP-SO under $530 \mathrm{~nm}$ light irradiation was evaluated using 1,3-diphenylbenzofuran (DPBF) as the ${ }^{1} \mathrm{O}_{2}$ indicator and $\mathrm{MB}$ as the standard $(\Phi \Delta=52 \%) .{ }^{17}$ It was found that TNP-SO showed a relatively high singlet-oxygen yield $(\Phi \Delta=49 \%)$ because of the heavy atom effect that facilitates intersystem crossing (ISC) of the excited energy (Fig. S2 $\dagger$ ). Notably, the formation of TNP-SH had minimal effect on the production efficiency of ${ }^{1} \mathrm{O}_{2}$. Therefore, the theranostic TNP-SO would be suitable for imaging-guided on-demand administration of photodynamic therapy of cancers expressing elevated levels of $\mathrm{H}_{2} \mathrm{~S}$.

In light of the low solubility of TNP-SO in aqueous solution, the nanoplatform Nano-TNP-SO was generated by encapsulating TNP-SO into the hydrophobic interior of water-dispersible silica nanocomposites according to a previously established method (Scheme 2). ${ }^{18}$ The loading efficiency of TNP-SO was determined with UV/vis absorbance spectra to be $0.96 \mathrm{wt} \%$. Characterization of the resulting Nano-TNP-SO was performed by dynamic light scattering (DLS) and transmission electron microscopy (TEM) (Scheme 2), which showed that the hydrodynamic diameter of Nano-TNP-SO remained at $98 \mathrm{~nm}$ and negligible aggregation was observed in aqueous solutions for days (Fig. S3†).

Next, the photophysical response of Nano-TNP-SO toward $\mathrm{H}_{2} \mathrm{~S}$ was evaluated in PBS buffer solutions ( $\mathrm{pH}$ 7.4). As shown in Fig. 2, the absorption maxima at 509 and $537 \mathrm{~nm}$ of NIR-BSO and 3I-BOD in silica nanocomposites showed a slightly bathochromic shift when compared to those in $\mathrm{CH}_{3} \mathrm{CN} / \mathrm{PBS}$. Interestingly, $\mathrm{H}_{2} \mathrm{~S}$-induced dramatic optical changes remained after the encapsulation of TNP-SO. The addition of NaHS elicited the generation of the NIR absorption at $677 \mathrm{~nm}$ and reduction of the absorption at $509 \mathrm{~nm}$ (Fig. 2a). Specifically, a significant increase in the fluorescence intensity at $712 \mathrm{~nm}$ was noted upon

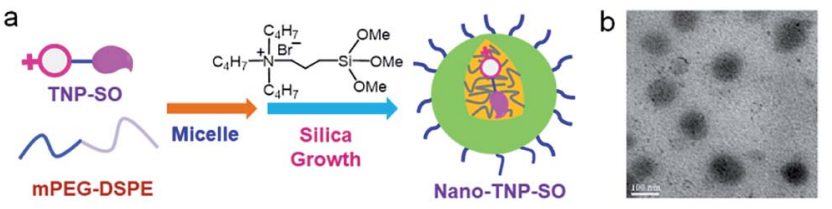

Scheme 2 (a) Schematic illustration of the generation of Nano-TNPSO. (b) Characterization of Nano-TNP-SO by TEM. Scale bars: $100 \mathrm{~nm}$. 

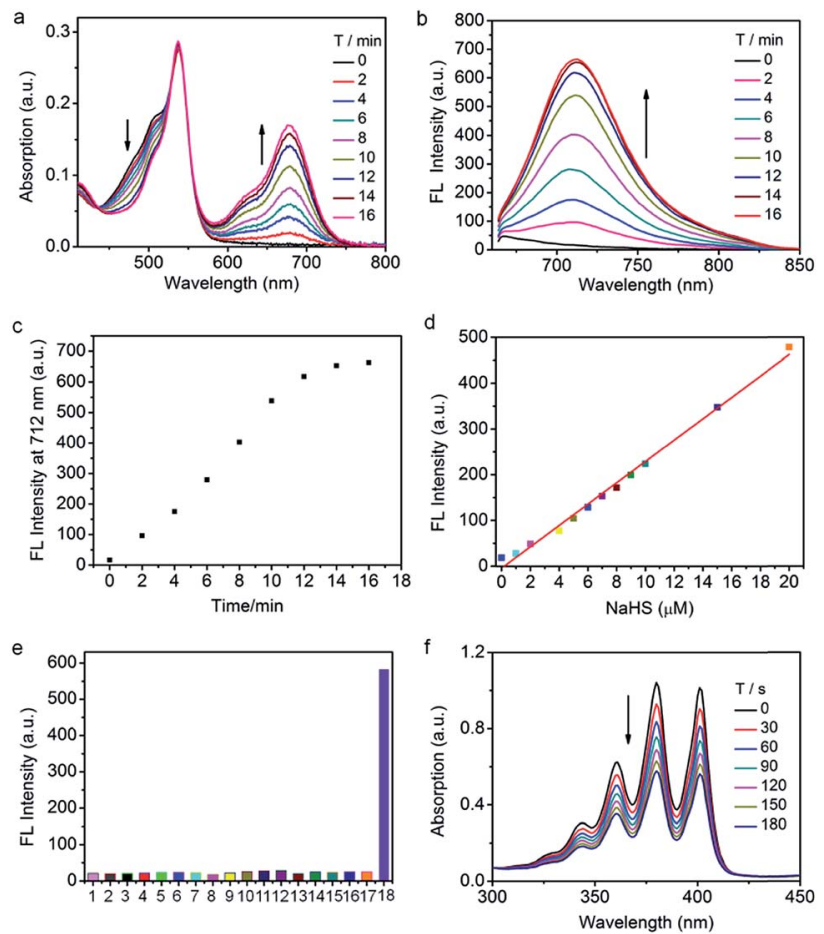

Fig. 2 Time-dependent (a) absorption and (b) emission spectral changes of Nano-TNP-SO (TNP-SO $5 \mu \mathrm{M}$ ) in the presence of $100 \mu \mathrm{M}$ $\mathrm{NaHS}$ in PBS solution ( $\mathrm{pH} 7.4$, room temperature). $\lambda_{\mathrm{ex}}=640 \mathrm{~nm}$. (c) Fluorescence intensity changes of Nano-TNP-SO at $712 \mathrm{~nm}$ in the presence of $100 \mu \mathrm{M}$ NaHS in PBS solution. (d) Linear correlation between fluorescence intensity changes of Nano-TNP-SO at $712 \mathrm{~nm}$ and the NaHS concentration. (e) Fluorescence intensity changes of Nano-TNP-SO in the presence of $100 \mu \mathrm{M} \mathrm{NaHS}$ and biologically relevant analytes in PBS ( $\mathrm{pH}$ 7.4). Data shown are for $1 \mathrm{mM}$ glutathione, $1 \mathrm{mM}$ cysteine, and $100 \mu \mathrm{M}$ for other analytes: (1) free; (2) $\mathrm{F}^{-}$; (3) $\mathrm{Cl}^{-}$; (4) $\mathrm{Br}^{-}$; (5) $\mathrm{I}^{-}$; (6) $\mathrm{NO}_{2}^{--}$; (7) $\mathrm{N}_{3}^{-}$; (8) $\mathrm{HCO}_{3}^{--}$; (9) $\mathrm{SO}_{4}{ }^{2-}$; (10) $\mathrm{HPO}_{4}{ }^{2-}$; (11) $\mathrm{ClO}^{-}$; (12) $\mathrm{H}_{2} \mathrm{O}_{2}$; (13) ${ }^{-} \mathrm{OAc}$; (14) $\mathrm{S}_{2} \mathrm{O}_{3}{ }^{2-}$; (15) GSH; (16) Cys; (17) Hcy; (18) $\mathrm{NaHS}$. (f) Photosensitized singlet oxygen generation unraveled by time-dependent absorption spectral changes of ABDA $(50 \mu \mathrm{M})$ upon $530 \mathrm{~nm}$ light irradiation of Nano-TNP-SO $(2 \mu \mathrm{M})$ in PBS solution.

excitation at $640 \mathrm{~nm}$ (Fig. 2b). Notably, the reaction time of 70 min between TNP-SO and $\mathrm{H}_{2} \mathrm{~S}$ in $\mathrm{CH}_{3} \mathrm{CN} / \mathrm{PBS}$ was relatively slow. In contrast, the reaction of TNP-SO with $\mathrm{H}_{2} \mathrm{~S}$ in Nano-TNPSO was markedly accelerated, reaching completion within 20 min (Fig. 2c). Moreover, the NIR fluorescence exhibited a linear increase with $\mathrm{H}_{2} \mathrm{~S}$ concentration $(0-20 \mu \mathrm{M})$, determining the detection limit to be $21 \mathrm{nM}$ which indicates the high sensitivity of Nano-TNP-SO for the detection of $\mathrm{H}_{2} \mathrm{~S}$ (Fig. 2d). Minimal optical responsiveness was observed in the presence of biologically related reactive sulfur (RSS), oxygen (ROS), and nitrogen species (RNS), indicative of its high selectivity for $\mathrm{H}_{2} \mathrm{~S}$ (Fig. 2e). Importantly, Nano-TNP-SO could also act as a good photosensitizer for the production of ${ }^{1} \mathrm{O}_{2}(\Phi \Delta=32 \%)$ in PBS upon exposure to $530 \mathrm{~nm}$ light (Fig. 2f and $\mathrm{S} 4 \dagger$ ). In addition, NanoTNP-SO exhibited good photostability (Fig. S5 $\dagger$ ) in aqueous solution, a critical factor for biomedical applications. Taken together, these advantages, including $\mathrm{H}_{2} \mathrm{~S}$-activated NIR emission light-up and efficient ${ }^{1} \mathrm{O}_{2}$ generation, make Nano-TNP-SO a promising tool for the identification of cancers and the subsequent imaging-directed on-demand administration of photodynamic anticancer therapy.

To explore the capability of Nano-TNP-SO as an imaging probe for guiding where to implement the light illumination of 3I-BOD to produce cytotoxic ROS, the ability to selectively visualize $\mathrm{H}_{2} \mathrm{~S}$-rich cancer cells was investigated. As shown in Fig. 3, HCT116 cells that express high levels of $\mathrm{H}_{2} \mathrm{~S}$ gave strong NIR fluorescence signals upon incubation with Nano-TNP-SO for $1 \mathrm{~h}$. The presence of a CBS inhibitor aminooxyacetic acid (AOAA) significantly attenuated the fluorescence image due to the inhibition of cellular generation of $\mathrm{H}_{2} \mathrm{~S}$. In contrast, increase of $\mathrm{H}_{2} \mathrm{~S}$ levels via stimulation with an allosteric CBS activator $S$-adenosyl-L-methionine (SAM) led to much stronger fluorescence. As expected, HepG2 cells with the minimized level of $\mathrm{H}_{2} \mathrm{~S}$ afford weak NIR fluorescence. AOAA and SAM also displayed a negligible effect on the fluorescence images (Fig. 3a). On this basis, it can be concluded that Nano-TNP-SO is selectively activated to light up NIR fluorescence in $\mathrm{H}_{2} \mathrm{~S}$-rich cancer cells, thus facilitating the accurate administration of PDT. According to the aforementioned imaging result, the cytotoxicity of Nano-TNP-SO toward HCT116 cells was then studied in the absence and presence of $530 \mathrm{~nm}$ light irradiation. MTT assay clearly demonstrated that Nano-TNP-SO showed low cytotoxicity in the absence of light. In contrast, greater cell death was seen in the case of HCT116 cells upon simultaneous treatment with Nano-TNP-SO and light irradiation at $530 \mathrm{~nm}$ $\left(100 \mathrm{~mW} \mathrm{~cm}^{-2}\right.$ ) for $10 \mathrm{~min}$ (Fig. 3b). The cell death induced by the Nano-TNP-SO mediated PDT was also evaluated using staining experiments with calcein acetoxymethyl ester/propidium iodide (calcein-AM/PI). As shown in Fig. 3c, treatment of cells with either Nano-TNP-SO or a $530 \mathrm{~nm}$ laser alone resulted

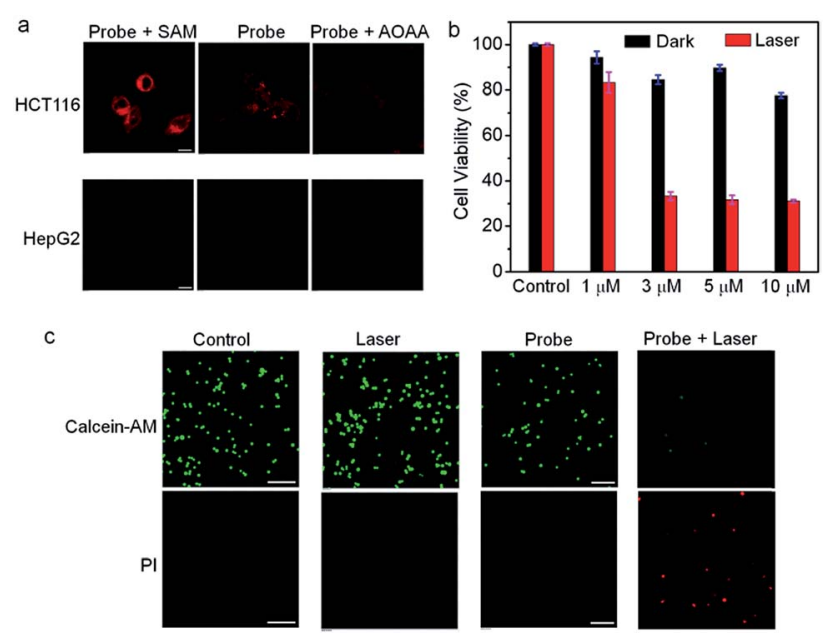

Fig. 3 (a) Visualization of $\mathrm{H}_{2} \mathrm{~S}$-rich cancer cells by confocal microscopy imaging. Cells incubated with Nano-TNP-SO (TNP-SO $5 \mu \mathrm{M}$ ) for $1 \mathrm{~h}$. For the assay of $\mathrm{H}_{2} \mathrm{~S}$ generation by the inhibitor and activator, cells pretreated with AOAA (1 mM) or SAM $(3 \mathrm{mM})$ for $1 \mathrm{~h}$ were loaded with Nano-TNP-SO for $1 \mathrm{~h}$. Scale bar $=10 \mu \mathrm{m}$. (b) The cytotoxicity of NanoTNP-SO toward HCT116 cells under dark and $530 \mathrm{~nm}$ light irradiation $\left(100 \mathrm{~mW} \mathrm{~cm}^{-2}\right.$ ). (c) Confocal fluorescence images of Calcein AM/PI pretreated HCT116 cells with different treatments. Scale bars: $100 \mu \mathrm{m}$. The $530 \mathrm{~nm}$ light power was $100 \mathrm{~mW} \mathrm{~cm}^{-2}$. 
in predominantly calcein AM-dependent green fluorescence, whereas PI-positive red signals were noted in cells upon treatment with Nano-TNP-SO (TNP-SO $5 \mu \mathrm{M}$ ) plus a $530 \mathrm{~nm}$ laser. These imaging results further demonstrated the low dark cytotoxicity and high photocytotoxicity of Nano-TNP-SO. Costaining experiments were employed to identify the location of Nano-TNP-SO utilizing commercially available Mito-Tracker Green and Lyso-Tracker Green (Fig. S6 $\dagger$ ). It was found that $\mathrm{H}_{2} \mathrm{~S}$ activated red fluorescence from Nano-TNP-SO showed good overlap with green fluorescence from Mito-Tracker Green or Lyso-Tracker Green, indicative of nonspecific intracellular localization.

Inspired by the aforementioned promising results, in vivo imaging-guided on demand PDT was evaluated. As shown in Fig. 4, a HCT116 tumor-bearing mouse treated with Nano-TNPSO displayed tumor-specific activation of NIR fluorescence as early as 1 min post-injection, whereas injection of Nano-TNP-SO into the normal muscle gave weak fluorescence. Region of interest measurements gave a NIR fluorescence signal ratio between the tumor and the normal site of 1.9 (5 min), 2.3 (10 $\mathrm{min}), 2.2$ (30 $\mathrm{min}$ ) and 2.0 (60 $\mathrm{min})$. In addition, such specific NIR fluorescence signals in the tumor region were significantly reduced upon the pretreatment of the tumor with aminooxyacetic acid (AOAA), a cystathionine- $\beta$-synthase (CBS) inhibitor. Since the overexpression of CBS contributes to increased $\mathrm{H}_{2} \mathrm{~S}$ levels in colon cancer, the inhibition of CBS activity by AOAA attenuated $\mathrm{H}_{2} \mathrm{~S}$ levels and thus led to the reduction of NIR fluorescence signals (Fig. $S 7 \dagger$ ). All these results indicated that Nano-TNP-SO can be specifically lit up in $\mathrm{H}_{2} \mathrm{~S}$ rich colorectal cancers, correspondingly identifying the spatial location of the PDT agent and the timing of implementation of the light illumination. We next assessed the PDT effect of NanoTNP-SO on tumors in HCTT116 tumor-bearing mice. After intratumor administration of Nano-TNP-SO and light irradiation, tumor growth was remarkably suppressed (Fig. 4c). As a control, minimal tumor growth inhibition was observed in mice treated with Nano-TNP-SO or laser exposure alone. The tumor inhibition efficiency of PDT was calculated to be around $82 \%$ at $10 \mathrm{~d}$ after treatment (Fig. 4d). The H\&E staining analysis demonstrated that significant cancer cell necrosis was noticed in the tumor section with both Nano-TNP-SO administration and light irradiation, indicative of high therapeutic efficiency toward the tumor cells by the PDT with Nano-TNP-SO. The tumor tissues in control groups including no treatment and treatment with a laser or Nano-TNPSO alone showed indiscernible necrosis, suggesting that NanoTNP-SO has negligible dark toxicity. In addition to no obvious changes of the body weights in mice with various treatments (Fig. 4e), no noticeable organ damage was observed in mice using H\&E stained images of major organs (heart, liver, spleen, lung, and kidney). These results clearly indicate the low toxic effect of PDT using Nano-TNP-SO.

\section{Live subject statement}

All animal experiments were performed in compliance with Chinese legislation on the Use and Care of Research Animals, and institutional guidelines for the Care and Use of laboratory animals established by the East China University of Science and Technology Animal Studies Committee. The experimental procedures and protocols were approved by this committee.
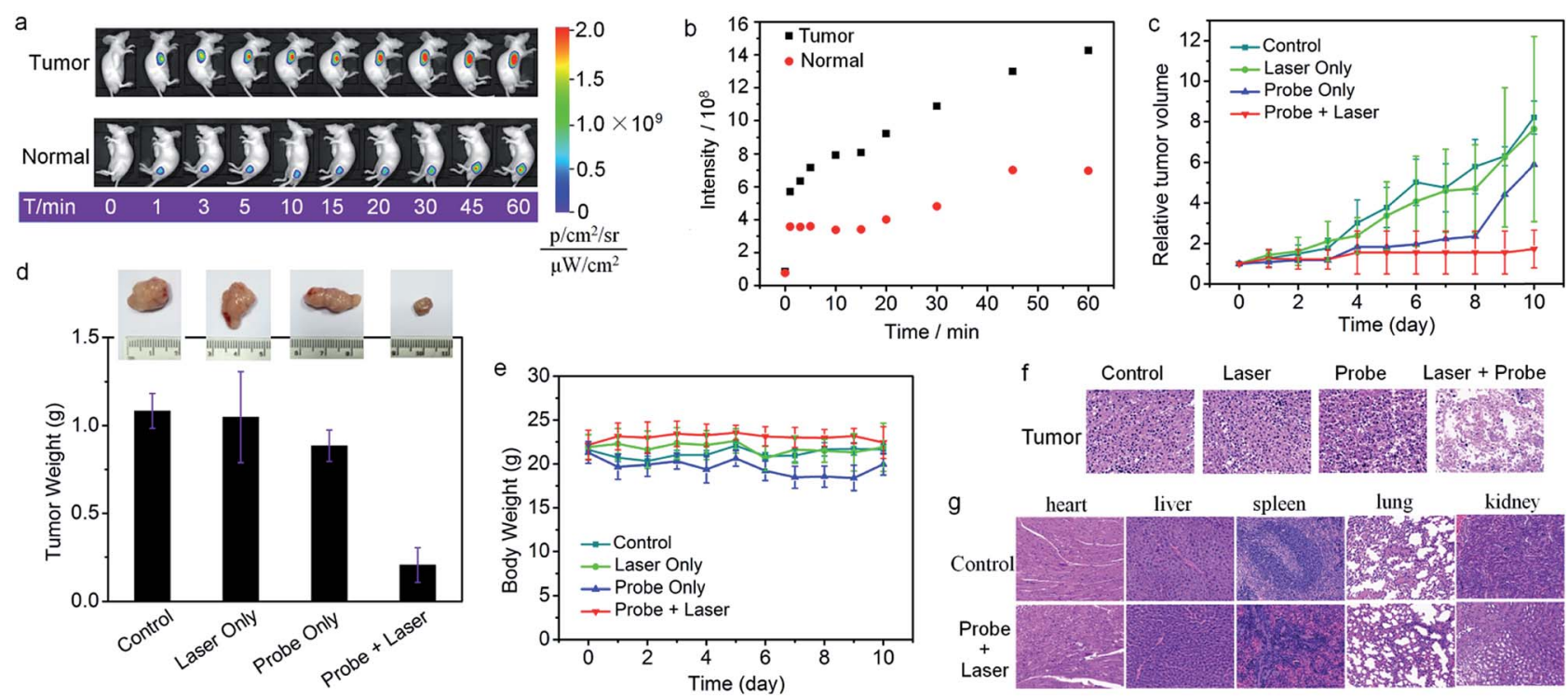

Fig. 4 (a) Tumor-specific activation of NIR fluorescence in a HCT116 tumor-bearing mouse treated with Nano-TNP-SO (25 nmol TNP-SO). Fluorescent images were taken at various time points after subcutaneous injection of Nano-TNP-SO into tumor and normal regions. (b) Region of interest measurements of the NIR fluorescence signal ratio between the tumor and the normal site injected with Nano-TNP-SO. (c) Tumor growth curves of mice in groups by administration of various treatments. (d) Tumor weight in different groups obtained on day 10 and the representative photographs of tumor tissues on day 10. (e) Body weight changes in mice with various treatments. (f) H\&E staining for tumors of mice after various treatments. (g) H\&E staining for major organs of mice without treatment and treated with Nano-TNP-SO and 530 nm light irradiation. Error bars represent the standard error of mean $(n=4)$. 


\section{Conclusions}

In conclusion, we have designed and synthesized a theranostic probe for activatable near-infrared emission-guided on-demand administration of PDT. The new obtained small molecule probe was encapsulated into the hydrophobic interior of silica nanocomposites for the fabrication of a nanoprobe with good aqueous solubility and photostability. This nanoprobe displayed $\mathrm{H}_{2} \mathrm{~S}$-dependent NIR emission light up, preferable for in vivo visualization of $\mathrm{H}_{2} \mathrm{~S}$-rich cancers. In addition, the nanoprobe could also act as a good photosensitizer for efficient production of ${ }^{1} \mathrm{O}_{2}$. By exploiting these advantages, we employed such a probe for in vivo PDT, which revealed that cancer imaging precisely directed where to implement the light illumination to produce cytotoxic ROS for on-demand cancer therapy, thus maximizing the therapeutic efficiency and minimizing side effects. We expect that our design approach could promote new advancements in the areas of cancer diagnosis and therapy.

\section{Conflicts of interest}

The authors declare no competing financial interest.

\section{Acknowledgements}

We gratefully acknowledge the financial support by the National Science Foundation of China (grant numbers 21672062, 31671309).

\section{Notes and references}

1 A. Umar, B. K. Dunn and P. Greenwald, Nat. Rev. Cancer, 2012, 12, 835.

2 (a) M. H. Lee, Z. Yang, C. W. Lim, Y. H. Lee, S. Dongbang, C. Kang and J. S. Kim, Chem. Rev., 2013, 113, 5071; (b) Q. Hu, M. Gao, G. Feng and B. Liu, Angew. Chem., Int. Ed., 2014, 53, 14225; (c) S. S. Kelkar and T. M. Reineke, Bioconjugate Chem., 2011, 22, 1879; (d) X. Chen, S. S. Gambhir and J. Cheon, Acc. Chem. Res., 2011, 44, 841; (e) H. Shi, R. T. K. Kwok, J. Liu, B. Xing, B. Z. Tang and B. Liu, J. Am. Chem. Soc., 2012, 134, 17972; (f) J. V. Jokerst and S. S. Gambhir, Acc. Chem. Res., 2011, 44, 1050; $(g)$ M. Gao, F. Yu, C. Lv, J. Choo and L. Chen, Chem. Soc. Rev., 2017, 46, 2237; (h) M. H. Lee, A. Sharma, M. J. Chang, J. Lee, S. Son, J. L. Sessler, C. Kang and J. S. Kim, Chem. Soc. Rev., 2018, 47, 28.

3 (a) X. He, J. Li, S. An and C. Jiang, Ther. Delivery, 2013, 4, 1499; (b) J. Tian, L. Ding, H.-J. Xu, Z. Shen, H. Ju, L. Jia, L. Bao and J.-S. Yu, J. Am. Chem. Soc., 2013, 135, 18850; (c) M. R. Ke, D. K. P. Ng and P. C. Lo, Chem. Commun., 2012, 48, 9065; (d) Z. Dong, L. Feng, Y. Hao, M. Chen, M. Gao, Y. Chao, H. Zhao, W. Zhu, J. Liu, C. Liang, Q. Zhang and Z. Liu, J. Am. Chem. Soc., 2018, 140, 2165.

4 (a) Q. Lin, C. Bao, Y. Yang, Q. Liang, D. Zhang, S. Cheng and L. Zhu, Adv. Mater., 2013, 25, 1981; (b) Y. Li, Y. Sun, J. Li, Q. Su, W. Yuan, Y. Dai, C. Han, Q. Wang, W. Feng and
F. Li, J. Am. Chem. Soc., 2015, 137, 6407; (c) H. S. Jung, J. Han, H. Shi, S. Koo, H. Singh, H.-J. Kim, J. L. Sessler, J. Y. Lee, J.-H. Kim and J. S. Kim, J. Am. Chem. Soc., 2017, 139, 7595.

5 (a) Z. Yang, J. H. Lee, H. M. Jeon, J. H. Han, N. Park, Y. He, H. Lee, K. S. Hong, C. Kang and J. S. Kim, J. Am. Chem. Soc., 2013, 135, 11657; (b) F. Wang, L. Zhou, C. Zhao, R. Wang, Q. Fei, S. Luo, Z. Guo, H. Tian and W. Zhu, Chem. Sci., 2015, 6, 2584; (c) Z. Zhao, H. Meng, N. Wang, M. J. Donovan, T. Fu, M. You, Z. Chen, X. Zhang and W. Tan, Angew. Chem., Int. Ed., 2013, 52, 7487; (d) J. Zhang, Z. F. Yuan, Y. Wang, W. H. Chen, G. F. Luo, S. X. Cheng, R. X. Zhuo and X. Z. Zhang, J. Am. Chem. Soc., 2013, 135, 5068; (e) X. Wu, X. Sun, Z. Guo, J. Tang, Y. Shen, T. D. James, H. Tian and W. Zhu, J. Am. Chem. Soc., 2014, 136, 3579; $(f)$ S. Bhuniya, S. Maiti, E.-J. Kim, H. Lee, J. L. Sessler, K. S. Hong and J. S. Kim, Angew. Chem., Int. Ed., 2014, 53, 4469; (g) C. Yan, Z. Guo, Y. Shen, Y. Chen, H. Tian and W.-H. Zhu, Chem. Sci., 2018, 9, 4959; (h) G. Yu, Z. Yang, X. Fu, B. C. Yung, J. Yang, Z. Mao, L. Shao, B. Hua, Y. Liu, F. Zhang, Q. Fan, S. Wang, O. Jacobson, A. Jin, C. Gao, X. Tang, F. Huang and X. Chen, Nat. Commun., 2018, 9, 766.

6 (a) H.-W. Liu, X.-X. Hu, K. Li, Y. Liu, Q. Rong, L. Zhu, L. Yuan, F.-L. Qu, X.-B. Zhang and W. Tan, Chem. Sci., 2017, 8, 7689; (b) R. Kumar, J. Han, H. Lim, W. X. Ren, J.-Y. Lim, J.-H. Kim and J. S. Kim, J. Am. Chem. Soc., 2014, 136, 17836; (c) G. Saravanakumar, J. Kim and W. J. Kim, Adv. Sci., 2017, 4, 1600124; (d) E.-J. Kim, S. Bhuniya, H. Lee, H. M. Kim, C. Cheong, S. Maiti, K. S. Hong and J. S. Kim, J. Am. Chem. Soc., 2014, 136, 13888; (e) X. Xu, P. E. Saw, W. Tao, Y. Li, X. Ji, S. Bhasin, Y. Liu, D. Ayyash, J. Rasmussen, M. Huo, J. Shi and O. C. Farokhzad, Adv. Mater., 2017, 29, 1700141; (f) C. Chu, H. Lin, H. Liu, X. Wang, J. Wang, P. Zhang, H. Gao, C. Huang, Y. Zeng, Y. Tan, G. Liu and X. Chen, Adv. Mater., 2017, 29, 1605928.

7 (a) X. Li, Y. Hou, X. Meng, C. Ge, H. Ma, J. Li and J. Fang, Angew. Chem., Int. Ed., 2018, 57, 6141; (b) J. B. Wu, T.-P. Lin, J. D. Gallagher, S. Kushal, L. W. K. Chung, H. E. Zhau, B. Z. Olenyuk and J. C. Shih, J. Am. Chem. Soc., 2015, 137, 2366; (c) G. Zheng, J. Chen, K. Stefflova, M. Jarvi, H. Li and B. C. Wilson, Proc. Natl. Acad. Sci., 2007, 104, 8989; (d) M. Chiba, Y. Ichikawa, M. Kamiya, T. Komatsu, T. Ueno, K. Hanaoka, T. Nagano, N. Lange and Y. Urano, Angew. Chem., Int. Ed., 2017, 56, 10418; (e) X. Zhen, J. Zhang, J. Huang, C. Xie, Q. Miao and K. Pu, Angew. Chem., Int. Ed., 2018, 57, 1.

8 (a) G. Collet, T. Lathion, C. Besnard, C. Piguet and S. Petoud, J. Am. Chem. Soc., 2018, 140, 10820; (b) K. Mitra, C. E. Lyons and M. C. T. Hartman, Angew. Chem., Int. Ed., 2018, 57, 10263; (c) S. Luo, X. Tan, S. Fang, Y. Wang, T. Liu, X. Wang, Y. Yuan, H. Sun, Q. Qi and C. Shi, Adv. Funct. Mater., 2016, 26, 2826; (d) Y. Min, J. Li, F. Liu, E. K. L. Yeow and B. Xing, Angew. Chem., Int. Ed., 2014, 53, 1012; (e) M. Karimi, P. S. Zangabad, S. B.-R. M. Ghazadeh, H. Mirshekari and M. R. Hamblin, J. Am. Chem. Soc., 2017, 139, 4584; ( $f$ ) L. Zhao, J. Peng, Q. Huang, C. Li, M. Chen, 
Y. Sun, Q. Lin, L. Zhu and F. Li, Adv. Funct. Mater., 2014, 24, 363; $(g)$ R.-F. Wang, H.-Q. Peng, P.-Z. Chen, L.-Y. Niu, J.-F. Gao, L.-Z. Wu, C.-H. Tung, Y.-Z. Chen and Q.-Z. Yang, Adv. Funct. Mater., 2016, 26, 5419.

9 (a) W. Tang, Z. Yang, S. Wang, Z. Wang, J. Song, G. Yu, W. Fan, Y. Dai, J. Wang, L. Shan, G. Niu, Q. Fan and X. Chen, ACS Nano, 2018, 12, 2610; (b) C. Zhu, D. Huo, Q. Chen, J. Xue, S. Shen and Y. Xia, Adv. Mater., 2017, 1703702.

10 (a) L. Cheng, C. Wang, L. Feng, K. Yang and Z. Liu, Chem. Rev., 2014, 114, 10869; (b) X. Li, N. Kwon, T. Guo, Z. Liu and J. Yoon, Angew. Chem., Int. Ed., 2018, 57, 11522.

11 (a) M. Triesscheijn, P. Baas, J. H. Schellens and F. A. Stewart, Oncologist, 2006, 11, 1034; (b) C. Robertson, D. H. Evans and H. Abrahamse, J. Photochem. Photobiol., B, 2009, 96, 1; (c) S. S. Lucky, K. C. Soo and Y. Zhang, Chem. Rev., 2015, 115, 1990.

12 (a) L. Huang, Z. Li, Y. Zhao, Y. Zhang, S. Wu, J. Zhao and G. Han, J. Am. Chem. Soc., 2016, 138, 14586; (b) D. E. J. G. J. Dolmans, D. Fukumura and R. K. Jain, Nat. Rev. Cancer, 2003, 3, 380; (c) X. Li, S. Lee and J. Yoon, Chem. Soc. Rev., 2018, 47, 1174.

13 (a) X. Li, D. Lee, J. Huang and J. Yoon, Angew. Chem., Int. Ed., 2018, 57, 9885; (b) X. Li, C.-Y. Kim, S. Lee, D. Lee, H. Chung, G. Kim, S.-H. Heo, C. Kim, K. Hong and J. Yoon, J. Am. Chem. Soc., 2017, 139, 10880; (c) Y. Ma, X. Li, A. Li, P. Yang, C. Zhang and B. Tang, Angew. Chem., Int. Ed., 2017, 56, 13752; (d) F. Hu, Y. Yuan, D. Mao, W. Wu and B. Liu, Biomaterials, 2017, 144, 53; (e) W. Wu, D. Mao, F. Hu, S. Xu, C. Chen, C. Zhang, X. Cheng, Y. Yuan, D. Ding, D. Kong and B. Liu, Adv. Mater., 2017, 29, 1700548; (f) Z. Zhou, J. Song, R. Tian, Z. Yang, G. Yu, L. Lin, G. Zhang, W. Fan, F. Zhang, G. Niu, L. Nie and X. Chen, Angew. Chem., Int. Ed., 2017, 56, 6492; (g) M. Li, X. Li, Z. Cao,
Y. Wu, J.-A. Chen, J. Gao, Z. Wang, W. Guo and X. Gu, Eur. J. Med. Chem., 2018, 157, 599.

14 (a) F. Wang, G. Xu, X. Gu, Z. Wang, Z. Wang, B. Shi, C. Lu, X. Gong and C. Zhao, Biomaterials, 2018, 159, 82; (b) C. Zhao, X. Zhang, K. Li, S. Zhu, Z. Guo, L. Zhang, F. Wang, Q. Fei, S. Luo, P. Shi, H. Tian and W. Zhu, J. Am. Chem. Soc., 2015, 137, 8490.

15 (a) G. Xu, Q. Yan, X. Lv, Y. Zhu, K. Xin, B. Shi, R. Wang, J. Chen, W. Gao, P. Shi, C. Fan, C. Zhao and H. Tian, Angew. Chem., Int. Ed., 2018, 57, 3626; (b) B. Shi, X. Gu, Q. Fei and C. Zhao, Chem. Sci., 2017, 8, 2150; (c) C. Szabo, C. Coletta, C. Chao, K. Módis, B. Szczesny, A. Papapetropoulos and M. R. Hellmich, Proc. Natl. Acad. Sci., 2013, 110, 12474; (d) B. Shi, Q. Yan, J. Tang, K. Xin, J. Zhang, Y. Zhu, G. Xu, R. Wang, J. Chen, W. Gao, T. Zhu, J. Shi, C. Fan, C. Zhao and H. Tian, Nano Lett., 2018, 18, 6411; (e) K. Zhang, J. Zhang, Z. Xi, L.-Y. Li, X. Gu, Q.-Z. Zhang and L. Yi, Chem. Sci., 2017, 8, 2776.

16 (a) Y. M. Yang, Q. Zhao, W. Feng and F. Y. Li, Chem. Rev., 2012, 113, 192; (b) Q. Miao, D. C. Yeo, C. Wiraja, J. Zhang, X. Ning, C. Xu and K. Pu, Angew. Chem., Int. Ed., 2018, 57, 1256; (c) Z. Guo, S. Park, J. Yoon and I. Shin, Chem. Soc. Rev., 2014, 43, 16; (d) L. Yuan, W. Lin, K. Zheng, L. He and W. Huang, Chem. Soc. Rev., 2013, 42, 622; (e) Q. Fei, X. Gu, Y. Liu, B. Shi, H. Liu, G. Xu, C. Li, P. Shi and C. Zhao, Org. Biomol. Chem., 2017, 15, 4072; $(f)$ L.-Y. Niu, Y.-Z. Chen, H.-R. Zheng, L.-Z. Wu, C.-H. Tung and Q.-Z. Yang, Chem. Soc. Rev., 2015, 44, 6143.

17 N. Adarsh, R. R. Avirah and D. Ramaiah, Org. Lett., 2010, 12, 5720 .

18 (a) B. Shi, X. Gu, Z. Wang, G. Xu, Q. Fei, J. Tang and C. Zhao, ACS Appl. Mater. Interfaces, 2017, 9, 35588; (b) B. M. Weckhuysen and J. Yu, Chem. Soc. Rev., 2015, 44, 7022. 